\title{
BMJ Open Findings from the development and implementation of a novel course consisting of both group and individual Alexander Technique lessons for low back pain
}

Joseph Little, ${ }^{1}$ Adam W A Geraghty (D) , ${ }^{1}$ Carolyn Nicholls, ${ }^{2}$ Paul Little (D) ${ }^{1}$

To cite: Little J, Geraghty AWA, Nicholls C, et al. Findings from the development and implementation of a novel course consisting of both group and individual Alexander Technique lessons for low back pain. BMJ Open 2022;12:e039399. doi:10.1136/ bmjopen-2020-039399

- Prepublication history and additional supplemental material for this paper are available online. To view these files, please visit the journal online (http://dx.doi.org/10.1136/ bmjopen-2020-039399).

Received 14 April 2020 Accepted 04 September 2021

D) Check for updates

(c) Author(s) (or their employer(s)) 2022. Re-use permitted under CC BY-NC. No commercial re-use. See rights and permissions. Published by BMJ.

${ }^{1}$ Primary Care Research Centre, Primary Care Population Sciences and Medical Education Unit, University of Southampton Faculty of Medicine,

Southampton, UK

${ }^{2}$ Brighton Alexander Technique College, Brighton, UK

Correspondence to Joseph Little;

J.Little@soton.ac.uk

\section{ABSTRACT}

Objectives (1) To develop a mixed course of individual and group lessons in the Alexander Technique (AT) for low back pain, and (2) to explore its: (a) effectiveness and (b) acceptability to both participant AT teachers and patients. Design Single-centre study, mixed methods.

Setting Members of the public in the Brighton area (community recruitment), and patients from six Hampshire General Practices (GP) (National Health Service (NHS) recruitment).

Participants People with chronic or recurrent low back pain; AT teachers.

Interventions Iterative development and implementation of a 10-lesson ( 6 group, 4 individual) AT course.

Outcome measures Perceptions from semistructured interviews analysed using inductive thematic analysis. Descriptive analysis of RMDQ (Roland-Morris Disability Questionnaire) over 12 weeks.

Results Thirty-nine participants with low back pain were included and 32 AT teachers were interviewed, 7 of whom taught on the course. Some participants had reservations, preferring only individual lessons, but the majority found the sharing of experience and learning in groups helpful. There was also concern regarding group teaching among some AT teachers, but most also found it acceptable. By 12 weeks, RMDQ score among participants fell from 10.38 to 4.39 , a change of -5.99 . 29 of $39(74 \%)$ participants had a clinically important reduction in RMDQ score of 2.5 or more.

Conclusion Some patients and practitioners had reservations about group AT lessons, but most found groups helpful. Further development is needed, but the course of individual and group lessons has the potential to cost-effectively deliver clinically important benefits to patients with back pain, who are known to improve little and slowly.

\section{INTRODUCTION}

Back pain has an estimated lifetime prevalence of 59\%-90\%, with an annual incidence of around $5 \%$ of the population. ${ }^{1}$ In the UK, $12.5 \%$ of all sick days are related to low back disorders, ${ }^{2}$ and persistent or major recurrent
Strengths and limitations of this study

- Iterative preliminary development of a novel course of mixed individual and group lessons of the Alexander Technique (AT).

- Similar inclusion criteria to previous studies of AT to permit some comparisons.

- Use of mixed methods to gain insights into the key perceptions and issues of acceptability for the course.

- Preliminary descriptive data from a sample allowing historical comparisons but no concurrent controls.

Small study population.

back pain has a poor long-term prognosis. ${ }^{3}$ Alexander Technique (AT) is included in the National Institute for Health and Care Excellence (NICE) systematic review section on selfmanagement as a postural therapy. ${ }^{4}$ AT aims to correct posture and upright support mechanisms through increasing a person's awareness of harmful habits of body use, allowing them to consciously move in a different way. ${ }^{5}$ These mechanisms involve improved coordination of the trunk, head and limbs, and improved motor control of postural muscles, factors which are usually operating poorly in individuals with chronic back pain. ${ }^{6-11}$ In the ATEAM trial, six lessons resulted in a 1.4 difference compared with usual care in the Roland-Morris Disability Questionnaire (RMDQ), whereas the minimum clinically important difference (MCID) for the RMDQ is of the order of 2-2.5. ${ }^{512}$ Longer courses of one-on-one lessons in the ATEAM trial were effective (RMDQ -3.4 compared with usual care) but not likely to be as cost-effective as other options that use group environments such as physiotherapy. ${ }^{5}$ Therefore, introducing AT group lessons alongside individual 
teaching may be a promising way to increase effectiveness without compromising cost efficiency.

Understanding and addressing potential barriers to uptake and implementation are essential for developing a new intervention. ${ }^{13}$ In particular, there are not only issues for participants in engaging with AT group lessons, but for AT teachers there may be important barriers-particularly any reduction in one-on-one lesson time ${ }^{13}$ as AT is traditionally delivered as a longer 1:1 intervention, including 'hands-on' assessment and guidance, in order to address students' individual body use in detail. In addition to concerns about lack of individual teaching time, hands-on work (light touches to direct attention and prompt changes in body use) is a critical part of AT teaching. ${ }^{14}$

There is no previously published research of group teaching of AT for back pain. However, there are some smallscale studies documenting the potential effectiveness of teaching AT in groups. A class-based AT intervention for 23 music students was found to reduce both playing-related and non-playing-related pain. Students reported that increased body awareness had led to these benefits. ${ }^{15}$ A small group (six to eight) AT intervention including some hands-on work was found to improve functional reach in a sample of 12 women over 65 vs a control group of $5 .^{16}$ An intensive 2-week group intervention including hands-on work for balance in an elderly sample of 19 individuals found some improvements in balance measures. ${ }^{17}$ Finally, a 14-week class-based intervention of AT was found to reduce tension in a sample of undergraduate piano students. ${ }^{18}$

Group physiotherapy and acupuncture have also been studied, and in at least two studies, groups were not seen as inferior to individual treatment by participants. ${ }^{19} 20$ The perception of group solidarity and common struggle with illness was valued by participants in both group physiotherapy and other group interventions including acupuncture and group exercise trials. ${ }^{19-21}$ In the group environment, participants also had the opportunity to share tips and advice with one another which enhanced their learning. ${ }^{20}{ }^{21}$ However, some participants may not benefit from the social aspect of group lessons due to the severity of their own physical or mental pain and/or disability. ${ }^{12}$ It is also possible that where disruptive individuals are present, or participants do not get on with one another, the group environment will be of diminished value. ${ }^{22}$

The development of the course was the primary aim of this study, but as it happened only modest changes were made to the initial format. We report the qualitative and quantitative results from the preliminary development of a mixed course of group and individual lessons of AT.

\section{METHODS}

\section{Overall study design}

This was a mixed-methods study. Qualitative work with AT teachers, both those participating in the delivery of the intervention, and a wider group of teachers who volunteered to be interviewed, was nested in the development and preliminary testing of the intervention in order to understand what the likely acceptability of the course would be to the AT profession and make alterations as necessary. Patient participants were also interviewed regarding their experience of the course. Quantitative measures were collected by using similar inclusion criteria to two previous studies that had good data on the natural history, ${ }^{57}$ and where there was a modest improvement in control groups, some provisional comparison could be made.

\section{Development of the intervention}

The group sessions included some hands-on work with each participant, to provide individualised feedback on body use, during which the teacher explained to the group what she/he was doing. Each participant was also given a book explaining AT to read in their own time (Body, Breath and Being), ${ }^{23}$ and mp3 talks developed by $\mathrm{CN}$ to explain aspects of the technique. Participants were encouraged to practise AT in between lessons.

The first group course consisted of eight participants taught by two teachers (one primary, the other assisting). Two initial group lessons $(90 \mathrm{~min}$ each) were followed by alternating individual lessons (40 min) and group lessons.

The initial course structure was determined based on discussion with our AT collaborators. Following the earliest interviews (after or during first group course) with participating teachers and patients about their experience of the course, the format was altered for all subsequent courses. Group lessons were made shorter $(60 \mathrm{~min})$, since participants struggled to concentrate for $90 \mathrm{~min}$. Group lessons were preceded by individual lessons to reduce initial misunderstanding, group size was also reduced (four to six participants), and groups were taught by a single teacher, both to improve efficiency and avoid the logistic difficulties of coordinating two teachers. No further alterations were made to the course following this (for course format, see online supplemental appendix A).

\section{Patient and public involvement}

Two patient and public involvement (PPI) collaborators were involved in the discussion of the research questions, outcome measures (particularly the importance of functioning as the key outcome), design of the study (whether a control group was necessary), initial development of the intervention and comments on study documents. Our PPI collaborators were not involved in the recruitment to, or the further conduct of, the study — but we gained feedback from study participants regarding the acceptability of all study procedures. A summary of the results will be sent to all participants.

\section{Participants and recruitment}

People with low back pain

Two primary pathways were used to recruit participantscommunity recruitment and National Health Service recruitment. For community sample, we used local paper advertisements, fliers placed in public places (eg, community centres) and direct referral by study AT teachers in the Brighton area. For NHS recruitment, General practices wrote to a random sample (to ensure a representative sample was invited) of patients who had seen the 
GP for back pain during the last 5 years. Potential participants were screened for eligibility by the trial manager and offered a place on the next available group course.

\section{Eligibility criteria}

Inclusion criteria: aged 18-65 years; ability to understand English (since outcomes validated in English); chronic or recurrent back pain (at least one previous episode recorded on GP electronic records; current episode at least 3 weeks in duration); and RMDQ score of 4 or more.

Exclusion criteria: previous lessons in AT; unable to reliably answer outcome questions (eg, severe and unstable mental illness, dementia or learning difficulty); unable to sit down due to pain (prevents elements of AT practice); pregnancy; age over 65 years (major pathology more likely-particularly cancer); current nerve root pain below the knee (sciatica); previous spinal surgery or planned major surgery; pending litigation for back pain; terminal illness; and any 'red flag' criteria suggesting sinister pathology.

\section{AT teachers}

In order to explore the acceptability of the course to the AT profession, we emailed the UK database of Society of Teachers of the Alexander Technique (STAT) teachers to recruit volunteer teachers for qualitative interviews about the issues surrounding group teaching in this format.

Teachers who were members of STAT and who were local to the Southampton study centre or the Brighton Alexander Technique College were recruited to deliver the intervention. These teachers were also interviewed regarding the issues surrounding group teaching in addition to their experience of teaching the course.

\section{Data collection}

Near the end of their course, student participants were also asked to take part in semistructured, qualitative telephone interviews about their experience of AT and of learning in a group format. Open-ended prompts were used and adapted as the interviews progressed where new issues were identified. Interviews were transcribed verbatim before analysis.

All participants completed a questionnaire at baseline and at 3 months (final follow-up) including basic demographic information; health-related quality of life $(\mathrm{EQ}-5 \mathrm{D})^{24}$; $\mathrm{RMDQ}^{5}{ }^{12}{ }^{25}$; days in $\operatorname{pain}^{5} 7^{26}$ and days interference with activity over past week; overall improvement $^{5727}$; modified enablement scale ${ }^{5728}$; and information regarding current/recent medication and treatment. Participants also completed a short weekly questionnaire prior to each lesson comprising only our primary feasibility outcomes: RMDQ, days in pain and days interference. The RMDQ was chosen as it is a standardised outcome measure for low back pain included in the COMET Initiative. ${ }^{29}$ Days in pain and days interference in normal activities were chosen in addition to the RMDQ as these were all used in the ATEAM and ASPEN Studies. ${ }^{57}$

\section{ANALYSIS}

\section{Qualitative analysis}

The transcripts were coded and analysed using inductive thematic analysis. ${ }^{30}$ The transcripts were read and reread. Through initial coding, an early coding frame was developed and discussed in detail by the qualitative researchers. Following agreement, the rest of the data were coded. From these codes, higher order themes were developed, drawing on frequent discussion. When themes had been developed, they were discussed and agreed with the full research group. This process was followed for two analyses: student participants with low back pain and AT teachers (both those who taught and did not teach as part of the intervention).

\section{Quantitative analysis}

Pretest and post-test scores of three outcome measures were analysed for means and SDs-RMDQ, days in pain, days interference.

\section{PPI input}

JM and NG provided input to the initial development of the intervention, the protocol, patient materials and study documents.

\section{RESULTS}

\section{Community recruitment}

Between 01 April 2016 and 12 April 2017, we screened 34 volunteers: 27 were eligible and were 26 recruited. One participant withdrew before their course started. The remaining 25 participants attended one of five group courses (between 03 May 2016 and 26 June 2017) (see figure 1).

\section{NHS recruitment}

Six GP practices recruited participants between 24 October 2017 and 09 May 2018. Seven hundred twentynine invitations were sent with 141 replies:

1. Interested and eligible on the RMDQ: 60.

2. Interested but not eligible on the RMDQ: 26.

3. Not interested: 55 .

Forty-three patients were screened: 26 were eligible and 23 agreed to participate.

Of those 23, 8 withdrew prior to commencing their group course; either due to the timing of their response to the invitation or the timing of the course dates. The size of this study meant that we had no alternative courses to offer. Fifteen participants attended one of four group courses between 01 January 2018 and 25 June 2018.

As such, of 49 initial recruits, 40 went on to receive the intervention. However, one participant was also found to be ineligible after pre-course screening (their responses were incorrect), and so their data have not been included.

\section{AT teacher interviews}

Our email was sent to 816 STAT members of whom 29 initially volunteered to be interviewed, and 25 consented and were interviewed. We also interviewed the seven 

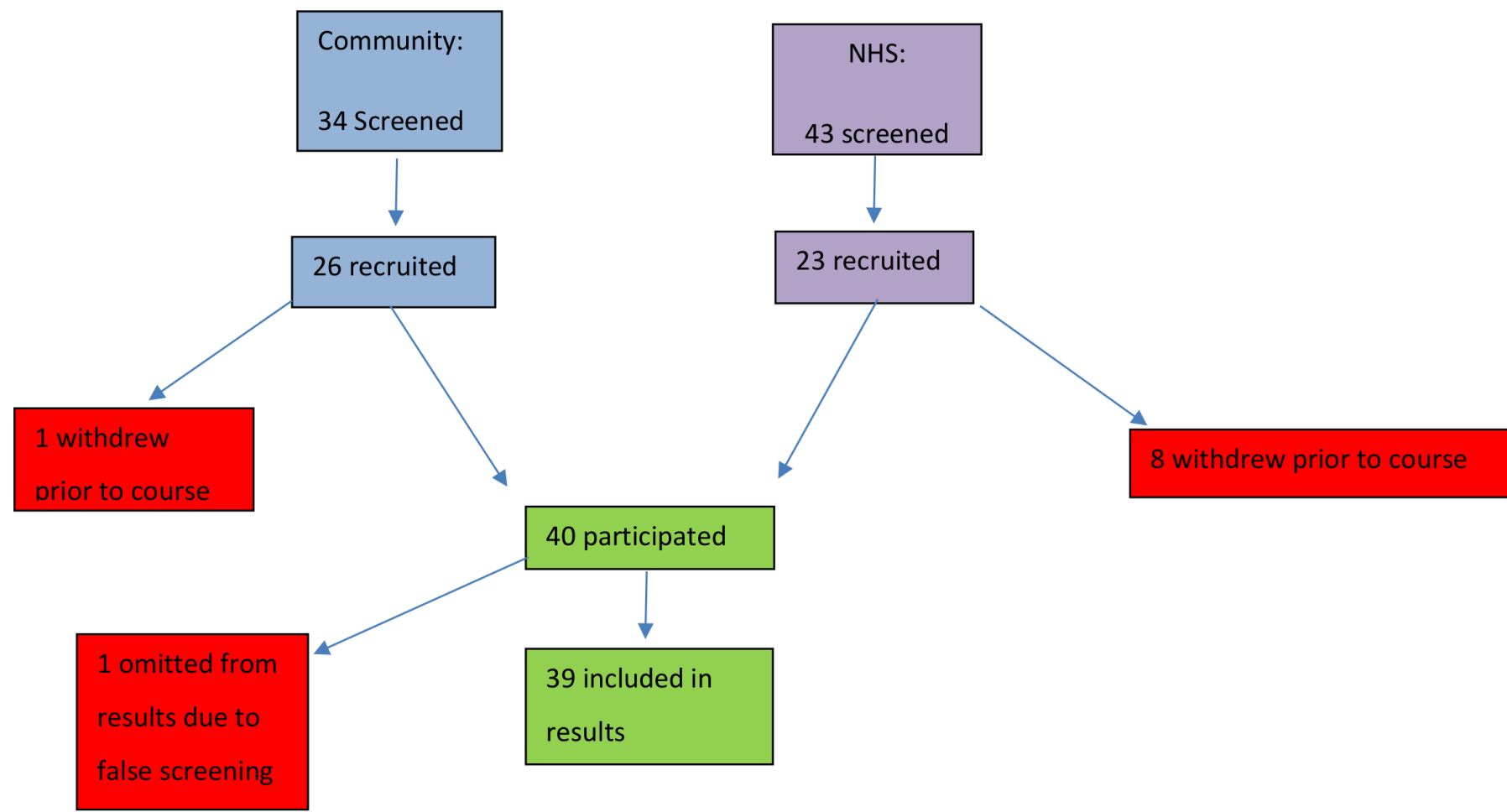

Figure 1 Flow diagram of participants.

teachers who taught group courses as part of the current study.

All teachers who volunteered had at least some group teaching experience (whether AT or non-AT; see table 1), although it was made clear in our initial email that this was not necessary for inclusion in the interviews. The sample was predominantly female although this may be as a result of the overall gender distribution in the profession. The sample included eight teachers who fulfil a senior role in STAT.

\section{Low back pain participant interviews}

A total of 32 of 39 student participants $(82 \%)$ were interviewed, 21 from the community recruitment phase and 11 from the NHS recruitment phase. Most participants interviewed were female, married or living with a partner, and from a wide educational background.

\section{Qualitative findings}

We developed three central themes (see below) regarding attitudes to group AT teaching. Of these, two originate from both AT teacher and student interviews. The third originates from AT teachers alone.

\section{Group teaching is better than no teaching}

The perception that some access to AT was better than no access was prevalent among the teachers. Teachers tended to take the view that although group teaching is not as optimal as private lessons in terms of depth of learning or rate of progression, it still has some merit, as in practice many people will not have the money or interest in attending a course of private lessons.

Group teaching was seen as an efficient way to providing students with a theoretical introduction to the technique,

\begin{tabular}{|c|c|c|c|c|}
\hline & Yes & No & & \\
\hline Experience teaching AT groups specifically for back pain & $18(56 \%)$ & $14(44 \%)$ & & \\
\hline Experience teaching AT groups (non-back pain) & $29(91 \%)$ & $3(9 \%)$ & & \\
\hline Experience teaching groups in other subjects & $11(34 \%)$ & $21(66 \%)$ & & \\
\hline Senior role in STAT & $8(25 \%)$ & $24(75 \%)$ & & \\
\hline Gender & $\begin{array}{l}\text { Male: } \\
7(22 \%)\end{array}$ & $\begin{array}{l}\text { Female: } \\
25 \text { (78\%) }\end{array}$ & & \\
\hline Number of years since qualification to teach AT & $\begin{array}{l}0<5 \\
7(22 \%)\end{array}$ & $\begin{array}{c}5<10 \\
8(25 \%)\end{array}$ & $\begin{array}{l}10<20 \\
9(28 \%)\end{array}$ & $\begin{array}{l}20+ \\
8(25 \%)\end{array}$ \\
\hline
\end{tabular}

AT, Alexander Technique; STAT, Society of Teachers of the Alexander Technique. 
and also effective when focused on imparting some basic AT skills to students (particularly semisupine, a type of AT practice that involves lying flat on one's back with bent knees), as well as practical everyday advice about body use.

I'd really stress that actually, actually group work isn't necessarily the best way, but at the same time, with the groups I've found, I have found people have had benefits very quickly. (T05)

This is echoed in the participant interviews. Some participants expressed a preference for individual lessons-and a small number would have opted for a course of pure individual lessons if possible. Regardless, these participants had an overall positive experience of the course and some raised the fact that they understood costing was an issue therefore were willing to accept the inclusion of group lessons in practice.

Um, no, no, I thought they were excellent. I mean, if, if it was my first choice I'd say all private lessons, but I think for more people to have the treatment more quickly maybe, then the combination is probably really good... Yeah, because that would, you know, we wouldn't want to delay other people having the course. (GREAT46)

Group teaching is valuable and has different strengths to individual teaching

This view was also prevalent among teachers and there was some significant crossover with the 'group teaching is better than no teaching' theme; many teachers held that although private lessons might be superior in the final analysis, group teaching still has its own strengths.

Generally, those who expressed this attitude see group teaching and individual teaching as each having their own strengths and weaknesses. Some would go as far as to saying that group and individual teaching are not directly comparable, and therefore the best approach in any given case is a matter of which is best suited to an individual student. It is worth noting however that most of the teachers who held this attitude would still recommend students have at least some private instruction alongside group lessons.

I've changed my mind about it. I think you can teach a lot in a group session... even [compared] to individual and what the feedback I get from the people from the groups, they-you know, some of them, they have been actually able to explore the technique even in more depth. (T026)

This was mirrored in the participant interviews with a majority expressing views akin to this. These participants tended to value the group support and solidarity highly and liked having the opportunity to share experiences and problems with the group. They valued the dual learning environments: focusing on their own specific problems in individual lessons and using group lessons as an opportunity to observe and interact with other participants and learn from one another's experiences.

Yeah, I think the, the mix of having one-to-ones and also sort of group sessions is really um interesting as well. I really liked having, I benefited from obviously having the one-to-ones, but equally having that opportunity to share experiences with people was, I think, um invaluable actually. (GREAT15)

Many of these participants felt that the balance between group and individual lessons was an ideal approach for them. However, others would have preferred a greater proportion of individual lessons as they found they learnt more on one-to-one. Despite their preference for individual lessons, these participants did find the group lessons useful in ways that individual teaching alone would not have provided.

Um, I preferred the one to one sessions, to be honest. But actually, the group sessions was good to... I mean, I, the thing is you're listening to everyone else's problems and issues, which is fine. Um, because it sort of, you pick up tips from other people, and how they've overcome it and things. (GREAT41)

Participants generally expressed an understanding that this was just a starting point for learning the AT and that they could go into much more depth with further study.

Because it, I do understand it and I think ten lessons probably is only scratching the surface. You know, I realise like probably I really should try and have another $10 / 20$, but it's expensive and I'm not too sure that I will do that. (GREAT12)

\section{Group teaching damages the AT profession}

A smaller but significant subsection of teachers interviewed expressed sympathy with this view. This attitude is partly supported by concern among these teachers that the current quality of AT group teaching present in the profession is very poor. They perceive that classes often comprise large groups of beginners with no experience of private lessons and are often taught by teachers with no training for group teaching.

Teachers expressing this view see a great deal of danger in the propagation of group teaching. They tend to express the view that if people attend only group lessons, they will not have learnt the technique to any practical degree of depth and will subsequently come away with an impression of AT that is both substandard and false. As a result, the reputation of AT as a whole will suffer the more group teaching becomes popularised.

The teachers are so keen on it because they say something is better than nothing, but something isn't better than nothing. Driving around in a half-maintained car isn't better than not driving. (T24)

Some teachers expressing these views were more positive about the intervention as proposed but others 
retained their concerns. These teachers would say that any attempt to teach people AT in groups is a non-starter by definition. AT has to be learnt in a one-on-one setting as it requires the constant physical attention of a teacher to achieve the kind of embodied learning needed for the technique to be effective. Even though the intervention included some hands-on teaching in group lessons, the total amount of hands-on time was still seen as insufficient by some.

It's just not the Alexander Technique [laughs]. If you've not got your hands on someone. I just don't think we're giving them the full shilling, they're not, they're not, it, it's a compromise, put it that way. (T028)

Those teachers who taught the course as part of this intervention expressed views generally in line with the first and second themes. However, intervention teachers did express some views that would fit with theme three regarding group teaching in general-but not regarding the course employed in this intervention. Teachers expressing views aligned with each of the three themes had variable experience of AT group teaching-there was no particular pattern in this regard. Only one teacher in the sample commented on having received training or group AT teaching of any kind.

\section{Quantitative findings}

Most student participants were female (30 of 39), in employment (29 of 39), married or living with a partner (25 of 29), and had a range of educational levels.
Follow-up for the primary outcome (RMDQ) was documented in 31 of $39(79.5 \%)$ participants who were active at baseline for the weekly data prior to lessons and 30 of $39(76.9 \%)$ for the final follow-up questionnaire at 12 weeks.

RMDQ score fell from 10.38 to 4.39 , a change of -5.99 by 12 weeks. Twenty-nine of 39 (74\%) participants had a reduction in RMDQ score of 2.5 or more. For the data collected at each lesson, there was an overall consistent downward trend in RMDQ scores across recruitment groups (see figure 2 and table 2).

Overall mean days in pain fell from 5.56 to 3.20, with a consistent downward trend in days in pain throughout the course (see table 2 ).

Mean days interference in normal activities fell from 1.64 to 0.74 , a change of -0.95 , with an overall downward trend across the weeks (see table 2).

\section{DISCUSSION}

This study reports the initial development of a course of combined group and individual lessons for the AT specifically for back pain, and the exploration of its acceptability among both patients and AT teachers.

\section{Strengths and weaknesses}

A strength of this study was the iterative development of this intervention based on feedback from teachers and participants. The inclusion criteria and key outcomes were very similar to previous randomised controlled trials of AT (ATEAM+ASPEN), so we can provisionally compare

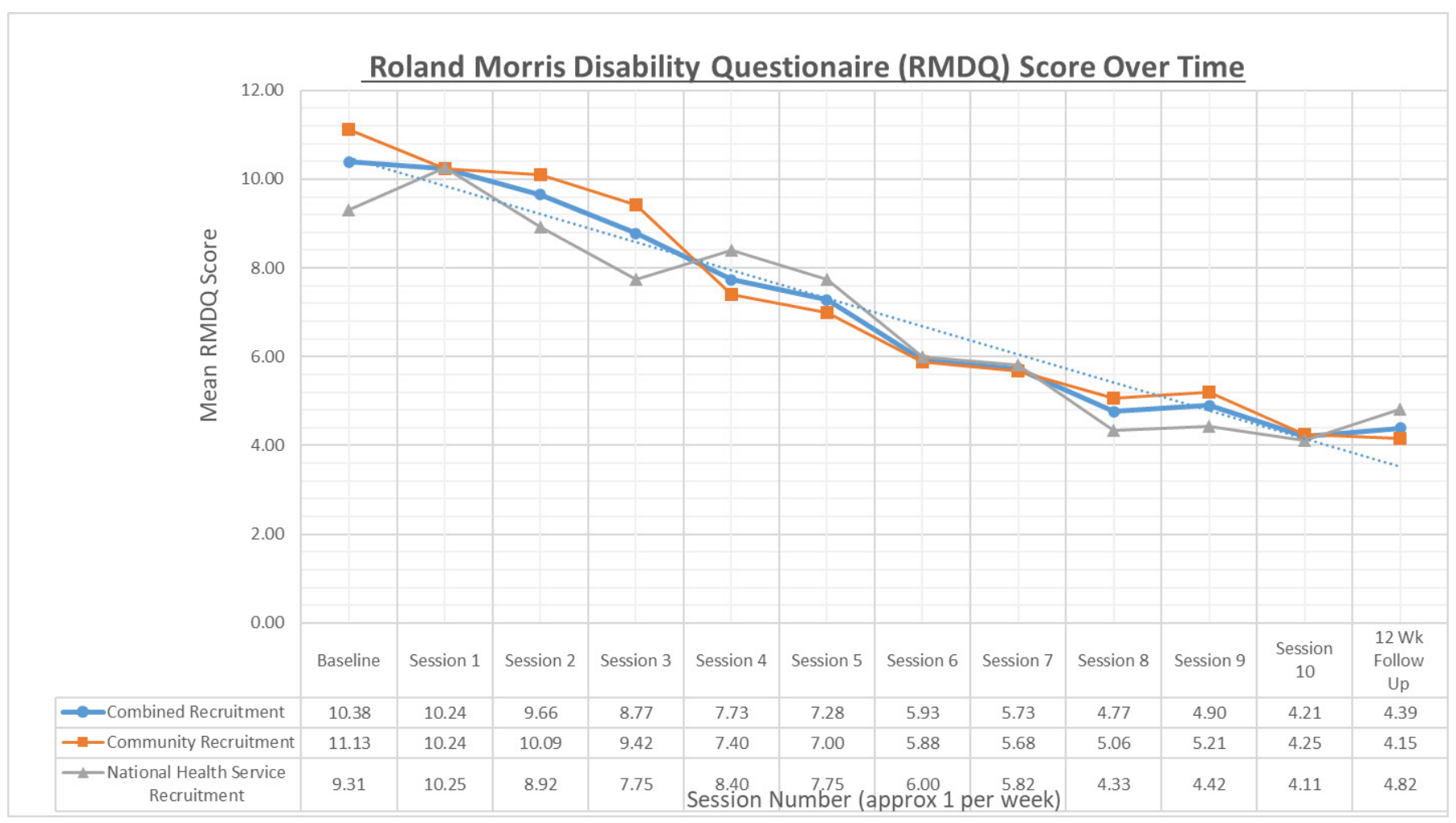

Figure 2 Days in pain over time. 
Table 2 Primary outcomes in participants with low back pain (baseline and final 12-week follow-up)

\begin{tabular}{|c|c|c|c|c|c|c|c|c|c|}
\hline & \multicolumn{3}{|c|}{ Combined recruitment } & \multicolumn{3}{|c|}{ Community recruitment } & \multicolumn{3}{|c|}{$\begin{array}{l}\text { National Health Service } \\
\text { recruitment }\end{array}$} \\
\hline & $\mathbf{N}$ & Mean & SD & $\mathbf{N}$ & Mean & SD & $\mathbf{N}$ & Mean & SD \\
\hline Baseline & 39 & 10.38 & 4.446 & 23 & 11.13 & 4.684 & 16 & 9.31 & 3.979 \\
\hline 12-week follow-up & 31 & 4.39 & 3.639 & 20 & 4.15 & 3.731 & 11 & 4.82 & 3.601 \\
\hline 12-week follow-up & 30 & 3.20 & 2.413 & 19 & 3.26 & 2.535 & 11 & 3.09 & 2.300 \\
\hline \multicolumn{10}{|c|}{ Days interference with usual activities (during the past week) } \\
\hline Baseline & 36 & 1.64 & 2.332 & 20 & 1.75 & 2.381 & 16 & 1.50 & 2.338 \\
\hline 12-week follow-up & 31 & 0.74 & 1.673 & 20 & 0.55 & 1.317 & 11 & 1.09 & 2.212 \\
\hline
\end{tabular}

RMDQ, Roland-Morris Disability Questionnaire.

the findings with the previous trials. We have also shown the viability of two distinct recruitment pathways. Finally, we have used mixed methods to gain better insight regarding patients' and practitioners' views regarding acceptability of the intervention. The small sample size and preliminary format warrant some caution regarding quantitative outcomes. The study was also uncontrolled so we cannot exclude non-specific changes over time, but since we know from the ATEAM and ASPEN Studies that participants with these inclusion criteria improve very little over time, we can be cautiously confident the intervention has the potential to be effective.

The drop-out rate pre-course commencement in the NHS recruitment group was higher than anticipated, but was very likely due to the lack of flexibility inherent in running a small feasibility study. We had no secondary course to offer if participants could not make the dates of the course in their area. We also had no replacement teachers immediately available who could be mobilised if a study teacher withdrew from the team-as one did causing a group cancellation. These issues would be remediable in a larger more flexible study-particularly with regard to flexibility around course dates available to participants.

The group teaching incorporated in this intervention should not be considered 'typical' within the AT profession at present-and a number of teachers interviewed remarked on this (both those who taught the course and those who did not). The group sessions included hands-on work and the numbers were kept small enough for this to be manageable for teachers. The groups were also accompanied by required reading and mp3 talks-again most groups do not do that. Furthermore, the course as a whole was designed by $\mathrm{CN}$ to be effective for back pain sufferers, although it is feasible for the course to be adapted for other musculoskeletal problems (knee, hip or neck pain). Although we do not have data on the use of additional resources (eg, use of mp3 talks), we recommend that future trials retain these 'atypical' elements in order to maximise the effectiveness of this course.

\section{Qualitative findings}

The reception of this intervention by patient participants and AT teachers was mostly positive-in many cases finding some advantages to individual lessons alonesupported by the evidence of positive perceptions of patients for group interactions in other conditions. ${ }^{31-33}$ However, there is some concern regarding group teaching among AT teachers. Much of the resistance to teaching AT group lessons from some teachers seems to come from the perception that group lessons cannot deliver adequate results and will therefore increasingly damage the reputation of the profession the more group teaching supplants individual teaching. The disagreement seems to be primarily about potential harm; providing group teaching has no negative effects on the profession as a whole, so group sessions are preferable (and vice versa). Therefore, if an intervention that incorporates group teaching can be shown to be effective, this may change many teachers' perceptions-and the quantitative and qualitative data from the current study suggest that is plausible.

It is also encouraging to note that while many intervention teachers went into this study with significant reservations about group teaching, at interview they were generally very positive about the intervention. Likewise, many of the teachers in the wider interview sample were better disposed towards this intervention than group teaching in general. As such, it will be important to stress the unconventional nature of the group teaching, (particularly small group size, allowing opportunity for hands-on work) included in this course as this is likely to make it more acceptable to those teachers with reservations about group teaching as it currently stands in the profession. Furthermore, it is important to ensure that participants 
understand that application of AT is a skill to be actively used and developed over time rather than a treatment in the conventional passive sense.

There remains the potential challenge of teaching the course for teachers with limited previous experience teaching groups (this is not included in STAT teachers training in the UK). This, and the negative perceptions of some teachers (see above), highlight the importance of developing robust materials for the course to maximise engagement and inform training.

Perceptions of the overall utility comparing group versus individual lessons from both teacher and patient interviews seemed to cluster around the view that groups have benefits they do not get from individual lessons alone, but if required to choose only one format then individual lessons will be more effective overall. Teacher attitudes to a mixed intervention were much more positive than to group teaching in isolation-even with some enthusiasm for this approach. Interviews with participants also supported previous qualitative research for group interventions with other modalities. ${ }^{11-1618}$ Most prominent was the value participants placed on group solidarity and the potential for learning interactively by engaging with one another's experiences.

\section{Quantitative findings}

The quantitative outcomes are promising. There were substantial and clinically important improvements in RMDQ ( -5.99 by 3 months). Since two previous trial data sets (ASPEN and ATEAM) document that this population improves little and slowly, the results suggest that the net effect over and above usual care (a reduction in 1 RMDQ score in the control group of the ATEAM Study, and similar in the ASPEN Study) could be reductions in RMDQ of the order of 4-5.5 compared with usual care. However, as initial studies can overestimate effect sizes, this could be diminished in a larger trial. Even allowing for this, it still seems plausible that the intervention could achieve the MCID for between-group differences, particularly as the intervention has not yet been optimised.

\section{Conclusion}

Overall, the qualitative analysis points towards acceptability for the most part among participants and AT teachers-although some maintain reservations. The quantitative data suggest that an intervention of this design could be a viable way of increasing effectiveness versus a short course without greatly increasing cost. Although caution is warranted, given the preliminary and uncontrolled nature of this study, a mixed course of individuals and group AT lessons appears to have the potential to cost-effectively produce clinically important changes in function and pain efficiently and is likely to be acceptable to both participants and practitioners.

\section{Future research}

Further iterative development of the materials for patients and teachers should improve engagement, acceptability and likely effectiveness to prepare the intervention for a full trial in low back pain which will also include a wider range of outcomes, including pain intensity and quality of life.

A similar course of individual and group AT lessons could also be developed for other common causes of musculoskeletal pain such as knee, hip or neck pain.

Acknowledgements We are very grateful to Nigel Gibson and Jane Magpie, our PPI collaborators, for their very helpful input to both the study design, outcomes and patient documents.

Contributors PL had the original idea for the study. CN developed the course and course materials, trained the teachers and ran several of the groups. JL managed all aspects of the study on a day-to-day basis, interviewed patients and teachers, analysed the qualitative and quantitative data, and wrote the first draft of the paper AWAG supervised the qualitative work. All authors developed the protocol and contributed to revisions of the paper. $\mathrm{JL}$ is the gaurantor for the overall content of this paper.

Funding The work was funded from three sources: a National Institute of Health Research (NIHR) Senior Investigator Award to PL; NIHR Research Capability funding; and a private donation from Mrs Ann Nussey.

Competing interests None declared.

Patient consent for publication Not required.

Ethics approval This study involves human participants and was approved by both University of Southampton (reference numbers: 24008 and 18780) and NHS ethics committees (REC committee: 17/EM/0185 IRAS number: 214897). Participants gave written informed consent to participate in the study before taking part.

Provenance and peer review Not commissioned; externally peer reviewed.

Data availability statement Data are available upon reasonable request. The data are available from Professor Little on request with a proposal for use of the data.

Supplemental material This content has been supplied by the author(s). It has not been vetted by BMJ Publishing Group Limited (BMJ) and may not have been peer-reviewed. Any opinions or recommendations discussed are solely those of the author(s) and are not endorsed by BMJ. BMJ disclaims all liability and responsibility arising from any reliance placed on the content. Where the content includes any translated material, BMJ does not warrant the accuracy and reliability of the translations (including but not limited to local regulations, clinical guidelines, terminology, drug names and drug dosages), and is not responsible for any error and/or omissions arising from translation and adaptation or otherwise.

Open access This is an open access article distributed in accordance with the Creative Commons Attribution Non Commercial (CC BY-NC 4.0) license, which permits others to distribute, remix, adapt, build upon this work non-commercially, and license their derivative works on different terms, provided the original work is properly cited, appropriate credit is given, any changes made indicated, and the use is non-commercial. See: http://creativecommons.org/licenses/by-nc/4.0/.

ORCID iDs

Adam W A Geraghty http://orcid.org/0000-0001-7984-8351

Paul Little http://orcid.org/0000-0003-3664-1873

\section{REFERENCES}

1 Hermans V. Research on work-related low back disorders. 1 ed. Brussels: Institute for Occupational Safety and Health, 2000.

2 Andersson GB. Epidemiological features of chronic low-back pain. Lancet 1999;354:581-5.

3 Croft PR, Macfarlane GJ, Papageorgiou AC, et al. Outcome of low back pain in general practice: a prospective study. BMJ 1998;316:1356-9.

4 NICE. Low back pain and sciatica in over 16's: assessment and management. Full guideline. nice org uk. NG59, 2016.

5 Little P, Lewith G, Webley F, et al. Randomised controlled trial of Alexander technique lessons, exercise, and massage (ATEAM) for chronic and recurrent back pain. BMJ 2008;337:a884.

6 Ferreira PH, Ferreira ML, Hodges PW. Changes in recruitment of the abdominal muscles in people with low back pain: ultrasound measurement of muscle activity. Spine 2004;29:2560-6. 
7 Little P, Stuart B, Stokes M, et al. Alexander technique and supervised physiotherapy exercises in back paiN (aspen): a fourgroup randomised feasibility trial. Efficacy Mech Eval 2014;1:1-82.

8 Cramer H, Mehling WE, Saha FJ, et al. Postural awareness and its relation to pain: validation of an innovative instrument measuring awareness of body posture in patients with chronic pain. BMC Musculoskelet Disord 2018;19:109.

9 Cacciatore T, Gurfinkel V, Horak F. Alteration of muscle tone through conscious intervention: increased adaptability of axial and proximal tone through the Alexander technique. Proc Int Soc posture and Gait Research 2007;18.

10 Cacciatore TW, Horak FB, Henry SM. Improvement in automatic postural coordination following Alexander technique lessons in a person with low back pain. Phys Ther 2005;85:565-78.

11 Gurfinkel V, Cacciatore TW, Cordo P, et al. Postural muscle tone in the body axis of healthy humans. J Neurophysiol 2006;96:2678-87.

12 Jordan K, Dunn KM, Lewis M, et al. A minimal clinically important difference was derived for the Roland-Morris disability questionnaire for low back pain. J Clin Epidemiol 2006;59:45-52.

13 Beattie A, Shaw A, Yardley L, et al. Participating in and delivering the ATEAM trial (Alexander technique lessons, exercise, and massage) interventions for chronic back pain: a qualitative study of professional perspectives. Complement Ther Med 2010;18:119-27.

14 The Constructive Teaching Centre, London. Available: https://www. constructiveteachingcentre.com/about-us/the-alexander-technique

15 Davies J. Alexander technique classes for tertiary music students: student and teacher evaluations of pre- and post-test audiovisual recordings. International Journal of Music Education 2020;38:194-207.

16 Dennis RJ. Functional reach improvement in normal older women after Alexander technique instruction. J Gerontol A Biol Sci Med Sci 1999;54:M8-11.

17 Batson G, Barker S. Feasibility of group delivery of the Alexander technique on balance in the community-dwelling elderly: preliminary findings. Act Adapt Aging 2008;32:103-19.

18 Ying LF, Evens Gl, Hashim MN, et al. Tension release in piano playing: teaching Alexander technique to undergraduate piano majors. Procedia Soc Behav Sci 2015;174:2413-7.

19 Raymond MJ, Burge AT, Soh S. Older inpatients' views on group PT. J Hosp Med 2016;5:358-62.
20 Asprey A, Paterson C, White A. 'All in the same boat': a qualitative study of patients' attitudes and experiences in group acupuncture clinics. Acupunct Med 2012;30:163-9.

21 O'Brien M, Dodd KJ, Bilney B. A qualitative analysis of a progressive resistance exercise programme for people with Parkinson's disease. Disabil Rehabil 2008;30:1350-7.

22 Mannerkorpi K, Gard G. Physiotherapy group treatment for patients with fibromyalgia--an embodied learning process. Disabil Rehabil 2003;25:1372-80.

23 Nicholls C, ed. Body, Breath and being: a new guide to the Alexander technique. 2nd ed, 2008.

24 EuroQol Research Foundation, 2019. Available: https://euroqol.org/

25 Roland M, Morris R. A study of the natural history of back pain. Part I: development of a reliable and sensitive measure of disability in lowback pain. Spine 1983;8:141-4.

26 Von Korff M, Ormel J, Keefe FJ, et al. Grading the severity of chronic pain. Pain 1992;50:133-49.

27 Beurskens AJHM, de Vet HCW, Köke AJA. Responsiveness of functional status in low back pain: a comparison of different instruments. Pain 1996:65:71-6.

28 Howie JG, Heaney DJ, Maxwell M, et al. Quality at general practice consultations: cross sectional survey. BMJ 1999;319:738-43.

29 Chiarotto A, Boers M, Deyo RA, et al. Core outcome measurement instruments for clinical trials in nonspecific low back pain. Pain 2018;159:481-95.

30 Braun V, Clarke V. Using thematic analysis in psychology. Qual Res Psychol 2006;3:77-101.

31 Emslie C, Whyte F, Campbell A, et al. 'I wouldn't have been interested in just sitting round a table talking about cancer'; exploring the experiences of women with breast cancer in a group exercise trial. Health Educ Res 2007;22:827-38.

32 Desveaux L, Harrison S, Lee A, et al. "We are all there for the same purpose": Support for an integrated community exercise program for older adults with HF and COPD. Heart Lung 2017;46:308-12.

33 Learmonth YC, Marshall-McKenna R, Paul L, et al. A qualitative exploration of the impact of a 12-week group exercise class for those moderately affected with multiple sclerosis. Disabil Rehabil 2013;35:81-8. 